$5-2004$

\title{
Foot and Ankle Forces During an Automobile Collision: the Influence of Muscles
}

\author{
Elizabeth C. Hardin \\ Cleveland Clinic Foundation \\ Anne Su \\ Cleveland Clinic Foundation \\ Antonie J. van den Bogert \\ Cleveland State University, a.vandenbogert@csuohio.edu
}

Follow this and additional works at: https://engagedscholarship.csuohio.edu/enme_facpub

Part of the Biomechanical Engineering Commons

How does access to this work benefit you? Let us know!

\section{Publisher's Statement}

NOTICE: this is the author's version of a work that was accepted for publication in Journal of Biomechanics. Changes resulting from the publishing process, such as peer review, editing, corrections, structural formatting, and other quality control mechanisms may not be reflected in this document. Changes may have been made to this work since it was submitted for publication. A definitive version was subsequently published in Journal of Biomechanics, 37, 5, (05-01-2004); 10.1016/j.jbiomech.2003.09.030

\section{Original Citation}

Hardin, E. C., Su, A., and van den Bogert, A. J., 2004, "Foot and Ankle Forces during an Automobile Collision: The Influence of Muscles," Journal of Biomechanics, 37(5) pp. 637-644.

This Article is brought to you for free and open access by the Mechanical Engineering Department at EngagedScholarship@CSU. It has been accepted for inclusion in Mechanical Engineering Faculty Publications by an authorized administrator of EngagedScholarship@CSU. For more information, please contact library.es@csuohio.edu. 


\title{
Foot and ankle forces during an automobile collision: the influence of muscles
}

\author{
E.C. Hardin, A. Su, A.J. van den Bogert* \\ Department of Biomedical Engineering. The Cleveland Clinic Foundation ND-2, 9500 Euclid Avenue, Cleveland, OH 44195, USA
}

\section{Introduction}

Lower limb injuries from automobile collisions impair and disable people, often permanently (MacKensie et al., 1993; Parenteau et al., 1996; Pattimore et al., 1990). These injuries have been ranked second in vehicle injury cost (Martin et al., 1997; Pletschen et al., 1990). Seatbelts and airbags do little to mitigate lower extremity injuries (Martin et al., 2000; Wilson et al., 2001), and with increasing airbag use in passenger cars, injuries to the extremities are increasing while those to the head and chest are decreasing (Martin et al., 1997, 2000). Some of the most debilitating injuries are to the foot and ankle. These have been are linked with foot pedal use, suggesting that muscle tensing is part of the injury mechanism (Parenteau et al., 1996; Partyka and Backaitis, 1995).

\footnotetext{
*Corresponding author. Tel.: +1-216-444-5566; fax: +1-216-4449198.

E-mail address: bogert@ bme.ri.ccf.org (A.J. van den Bogert).
}

Muscle properties can affect lower extremity loading during a collision in several ways. One way is through forces generated by voluntary muscle activation such that as from braking. Secondly, once an impact occurs, muscle forces influence the body's movement, and hence have an effect on the collisions with the vehicle's interior. Once collisions occur, muscle forces are not constant, but will increase in response to rapid muscle stretching that may occur during impact. These responses cannot be captured by simple models such as a spring, or a spring and dashpot (Winters, 1990). The three-element Hill-based muscle model, implemented as a first-order differential equation, has been shown to predict realistic responses of muscles to rapid stretch (Cole et al., 1996b).

The influence of muscle tension on ankle and rearfoot injuries from an automobile collision has been investigated with cadavers and numerical simulations (Cappon et al., 1995; Funk et al., 2002; Kitagawa et al., 1998a, b; Manning et al., 1998; McMaster et al., 2000). In lieu of active muscles, forces have been applied to cadaveric Achilles tendons, but this neglects the mechanical 
properties of active muscle tissue. Also, these experiments do not include whole body movement following impact. Most computational models only include triceps surae musculature and omit muscle's well-known mechanical properties, such as force-length and forcevelocity relationships. Instead, muscles are modeled using spring elements with unknown stiffness property values (Kitagawa et al., 1998a, b), and nonlinear tension elements in parallel with Maxwell elements (Dubbeldam et al., 1999), incorporating viscoelasticity. More recently, lower extremity ligaments and the Achilles tendon have been modeled with finite element models (FEM), but still exclude the mechanical properties of muscle (Beillas et al., 2001; Iwamoto et al., 2000; Tamura et al., 2001).

A Hill-based muscle model was recently implemented in commercial software and used to simulate forces during a footwell intrusion (Cappon et al., 1999). This muscle model did not include series elasticity, which may have resulted in overestimation of impact forces on the skeleton. Vehicle deceleration was not simulated in this model, and the influence of muscle activation on forces caused by vehicle deceleration thus remains unclear.

The aim of this study was, therefore, to use a realistic muscle model and determine how muscle activation influences the foot and ankle forces during an automobile collision. Impact responses were predicted for three activation states, no muscle activation, minimal muscle activation, and maximal muscle activation. The specific dependent variables were the peak external rearfoot force, Achilles tendon force, and ankle joint force.

\section{Methods}

A 2-D musculoskeletal model was created which simulated braking with the right leg (Fig. 1). The model had two legs consisting of three rigid bodies each, the right and left thighs, right and left lower legs, and right and left feet. The pelvis, trunk, arms and head were represented by one segment (Winter, 1990). Segment lengths were obtained for a 50th percentile male (Robbins, 1983) having a body mass of $76.6 \mathrm{~kg}$ and height of $1.75 \mathrm{~m}$. Segment masses and inertial properties were based on Dempster's work (Dempster, 1956; Winter, 1990). All segments were connected by frictionless hinge joints. The model had nine kinematic degrees of freedom and equations of motion were generated using SD/FAST (PTC, Needham MA, USA). The model was implemented with forward dynamics to simulate motion under the influence of automobile deceleration and muscle activation.

Six right-side muscle groups were included in the model, the glutei, hamstrings, rectus femoris, vasti, gastrocnemius, and soleus. Each muscle group was represented by a Hill-based model with two components, a contractile element (CE) and series elastic element (SEE, Fig. 2). Muscles were given constant moment arms and properties (Table 1) that have been used previously (Gerritsen et al., 1998). Passive elastic properties were modeled as torques in hip, knee and ankle joints that were functions of two joint angles (Reiner and Edrich, 1999), thus including the passive coupling between joints which is characteristic of biarticular muscles.

Vehicle contact surfaces were modeled as line segments and the vehicle interior was modeled according to dimensions for a 1992 Ford Taurus from Ford Motor Company (Detroit, MI, USA; Fig. 1). Contact between each foot and the toepan and floorpan was modeled by 22 discrete contact elements, each producing a force perpendicular to the surface depending on penetration $p$ and its velocity $\dot{p}$ (Wright et al., 1998):

$F_{\text {normal }}=a p^{b}+c p^{d} \dot{p}^{e}$.

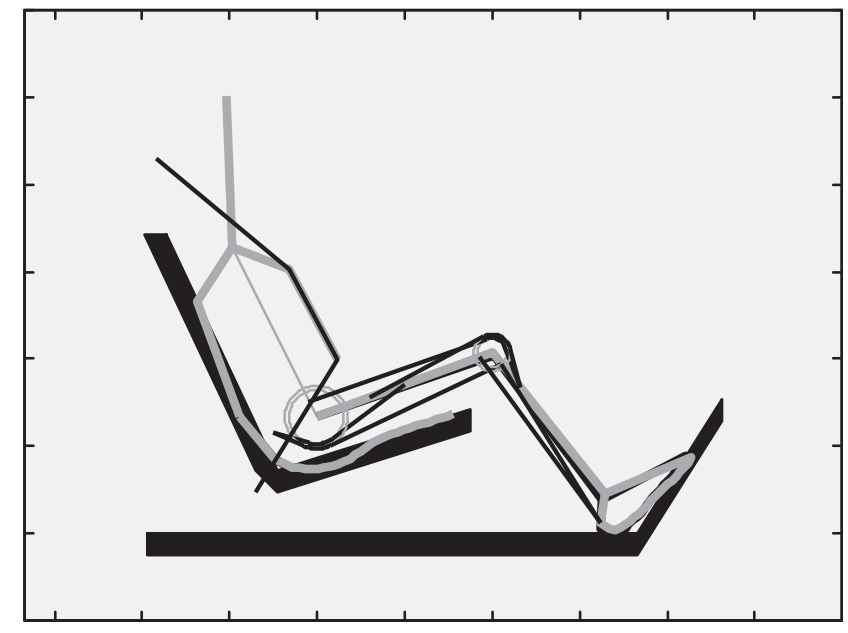

Fig. 1. The seven body segments represented in the model (gray), the six muscles (black), the contact surfaces and the seat restraints. The passive left leg is resting on the toepan and the active right leg (gray) is braking. The model is shown while braking prior to the crash during minimal muscle activation.

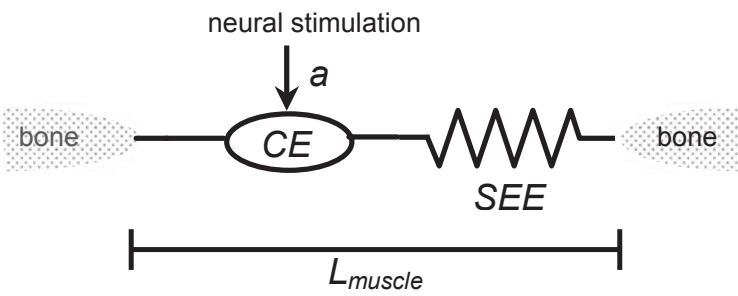

Mechanical properties:

State equation:

$F_{C E}=f_{1}\left(L_{C E}, d L_{C E} / d t, a\right)$

$$
F_{S E E}=f_{2}\left(L_{S E E}\right)
$$

Fig. 2. The Hill-based muscle model, consisting of a contractile element (CE) and a series elastic element (SEE). Activation level of the muscle is designated by $a$. 
Table 1

The muscle properties for the models MN and MX. $F_{\max }$ is the maximal isometric force of the CE. $L_{\mathrm{CEopt}}$ is the optimal length of the CE. Width is the maximal relative length change of the CE; $L_{\text {slack }}$ is the slack length of the SEE; $L_{\text {muscle }}$ is the length of the muscle when the hip, knee and ankle are

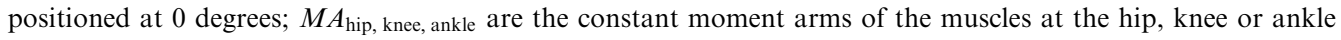

\begin{tabular}{|c|c|c|c|c|c|c|c|c|}
\hline Muscle & $F_{\max }(\mathrm{N})$ & $L_{\text {CEopt }}(\mathrm{m})$ & $L_{\text {slack }}(\mathrm{m})$ & Width (proportion of $L_{\text {CEopt }}$ ) & $L_{\text {muscle }}(\mathrm{m})$ & $M A_{\text {hip }}(\mathrm{m})$ & $M A_{\text {knee }}(\mathrm{m})$ & $M A_{\text {ankle }}(\mathrm{m})$ \\
\hline Glutei & 1705 & 0.200 & 0.157 & 0.625 & 0.271 & -0.062 & 0 & 0 \\
\hline Hamstrings & 1770 & 0.104 & 0.334 & 1.197 & 0.383 & -0.072 & -0.034 & 0 \\
\hline Rectus femoris & 663 & 0.081 & 0.398 & 1.443 & 0.474 & 0.034 & 0.050 & 0 \\
\hline Vasti & 7403 & 0.093 & 0.223 & 0.627 & 0.271 & 0 & 0.042 & 0 \\
\hline Gastrocnemius & 1639 & 0.055 & 0.420 & 0.888 & 0.404 & 0 & -0.02 & -0.053 \\
\hline Soleus & 3883 & 0.055 & 0.245 & 1.039 & 0.201 & 0 & 0 & -0.053 \\
\hline
\end{tabular}

The parameters for each contact point were chosen to optimally fit force-deformation data from a dynamic impact test on the heel with soft shoe (Aerts and De Clercq, 1993): $a=8839, b=1.066, c=376.8, d=$ $0.4456, e=0.3896$, with $F, p$ and $\dot{p}$ expressed in $\mathrm{N}, \mathrm{m}$, and $\mathrm{ms}^{-1}$, respectively. Contact between the thigh segments and seat pan was modeled with 30 discrete contact elements in each thigh. The contact model between the torso and the seat back was composed of 2 discrete contact elements. These seat pan and seat back contact elements were linear viscoelastic elements with elastic properties determined by assuming a total seat deformation of $2 \mathrm{~cm}$ under full body weight $\left(k_{\text {seat pan }}=657.12 \mathrm{~N} \mathrm{~m}^{-1} ; k_{\text {seat back }}=19,715 \mathrm{~N} \mathrm{~m}^{-1}\right)$ and critical damping properties $\left(c_{\text {seat pan }}=57.92 \mathrm{~N} \mathrm{~s} \mathrm{~m}^{-1}\right.$; $c_{\text {seat back }}=1737.5 \mathrm{~N} \mathrm{~s} \mathrm{~m}^{-1}$ ). Forces parallel to the surface of all contact points were generated with a Coulomb friction model approximation (Cole et al., 1996a), using a friction coefficient of 1.0. The lap belt restraint was modeled as linear spring between vehicle and torso allowing 15\% deformation at 11,120 N (Code of Federal Regulations, 2000), providing a force to the maximum abdominal protrusion (Robbins, 1983). The shoulder belt restraint was modeled as a spring which permitted $100 \%$ deformation at $11,120 \mathrm{~N}$ and provided a force to the substernum (Robbins, 1983).

Initial conditions were obtained by performing a 4-s simulation of static braking without vehicle deceleration. Suitable static muscle stimulation levels were found by minimizing the sum of the six muscle activation levels, while requiring a final steady state with pedal force of $400 \mathrm{~N}$ (Mazzae et al., 1999) and a distance between heel and toepan of $5 \mathrm{~cm}$. This represented a realistic driving posture (Robbins, 1983), with braking performed by the forefoot only (Manning et al., 1998) and with minimal effort (Fig. 1). The optimization was performed with a simulated annealing algorithm (Goffe et al., 1994).

Three models were tested: maximal muscle activation (MX, panic braking), minimal muscle activation (MN), and no muscles (NM). Muscle activation levels for the MN model, found using the optimization described above, were $20.4 \%$ for the vasti group and $22.5 \%$ for

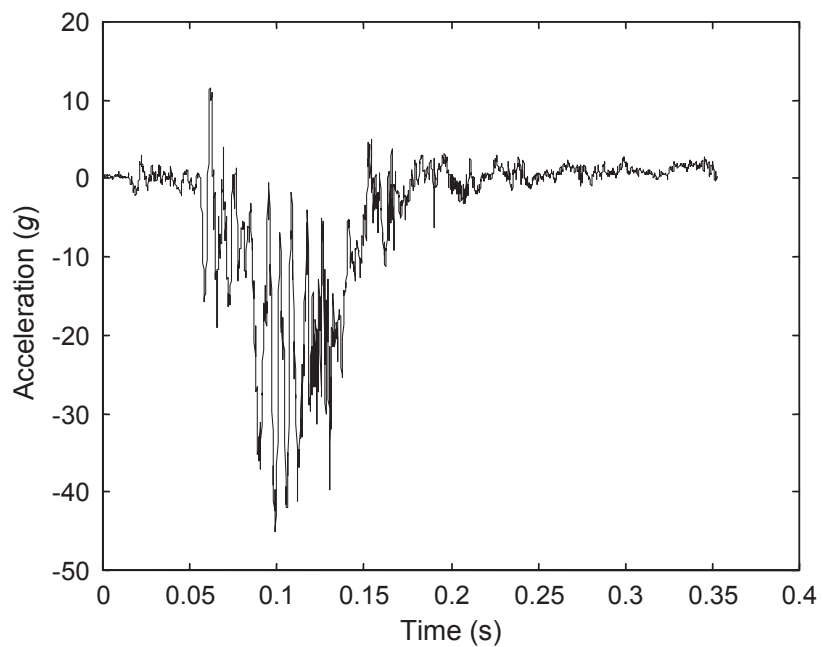

Fig. 3. The deceleration pulse applied to the contact surfaces of the model obtained from the National Highway Transportation and Safety Administration (NHTSA, crash \#2075).

the gastrocnemius with all of the other muscles not activated. Each model was placed on the vehicle contact surfaces using initial segment positions and velocities, and muscle contractile element lengths that existed at the end of the simulation of static braking with minimal muscle activation (MN) with the exception of MX. It was necessary to set the $\boldsymbol{L}_{\mathrm{CE}}$ at slack length for MX in order to decrease muscle force transients. To simulate a frontal crash, vehicle deceleration data were obtained from the National Highway Transportation and Safety Administration (NHTSA, http://www-nrd.nhtsa.dot. gov/database/nrd-11/veh_db.html, test no. 2075; Fig. 3). This test was a vehicle-to-vehicle frontal impact test of a 1992 Ford Taurus LX with a speed of $61.5 \mathrm{kmh}^{-1}$ and was used in a previous lower extremity injury study (Digges et al., 1995). The data were twice integrated and used to generate horizontal displacement of the vehicular contact surfaces. Toepan intrusion was not included in the model. Crashes were simulated with each of the three models (Fig. 4) and the following variables were calculated (Fig. 5): peak rearfoot ground reaction force $\left(F_{\mathrm{RF}}\right)$, peak Achilles tendon force $\left(F_{\mathrm{AT}}\right)$, 


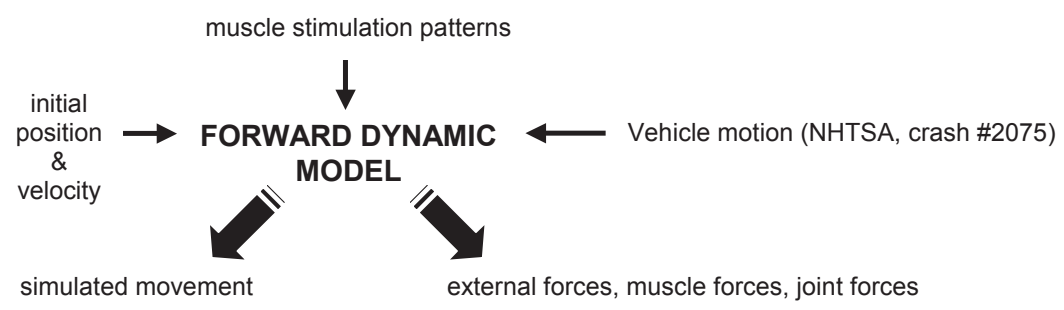

Fig. 4. Data flow in the forward dynamics analysis which simulated body motion under the influence of automobile deceleration and muscle activation. Vehicle motion data were applied to the contact surfaces and the model was given initial conditions that were solved previously with the optimization of minimal muscle activation for the static driving task.

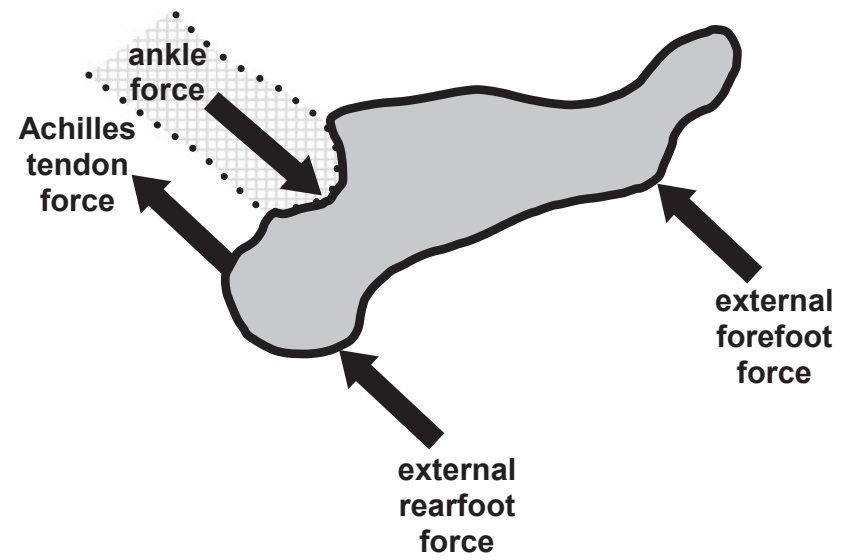

Fig. 5. Free body diagram of the forces on the foot. The dependent variables were peak external rearfoot force $\left(F_{\mathrm{RF}}\right)$, peak Achilles tendon force $\left(F_{\mathrm{AT}}\right)$, and peak ankle force $\left(F_{\mathrm{AJ}}\right)$, where $F_{\mathrm{AT}}=F_{\text {gastrocnemius }}+$ $F_{\text {soleus }}$ and $F_{\mathrm{AJ}}=F_{\text {muscles across ankle }}+F_{\text {bone-on-bone at ankle. }}$.

and peak ankle joint force $\left(F_{\mathrm{AJ}}\right)$. Ankle joint force was calculated as the resultant force on the joint $\left(F_{\mathrm{AJ}}=\left|\vec{F}_{\text {muscles across ankle }}+\vec{F}_{\text {bone-on-bone at ankle }}\right|\right)$.

\section{Results}

There were large differences in external and internal force responses between the three models. The peak external force $\left(F_{\mathrm{RF}}\right)$ was greatest for the models with minimal muscle activation (MN) and no muscles (NM) (1202 N and $1178 \mathrm{~N}$, Fig. 6). These produced peak values that were twice that of the panic braking model (MX, 629 N, Fig. 6). Muscle activation changed the Achilles tendon force dramatically. The panic braking model (MX) produced a peak Achilles tendon force four times that exhibited by the model with minimal muscle activation (MN), $6445 \mathrm{~N}$ versus $1430 \mathrm{~N}$ (Fig. 7). In both cases, the impact resulted in a doubling of tendon force, relative to the force that existed during braking, prior to impact. Muscle activation had notable effects on the ankle joint force as well. The greatest peak ankle force occurred in the MX model $(10,120 \mathrm{~N})$ whereas the lowest was found in the NM model (1451 N, Fig. 8).

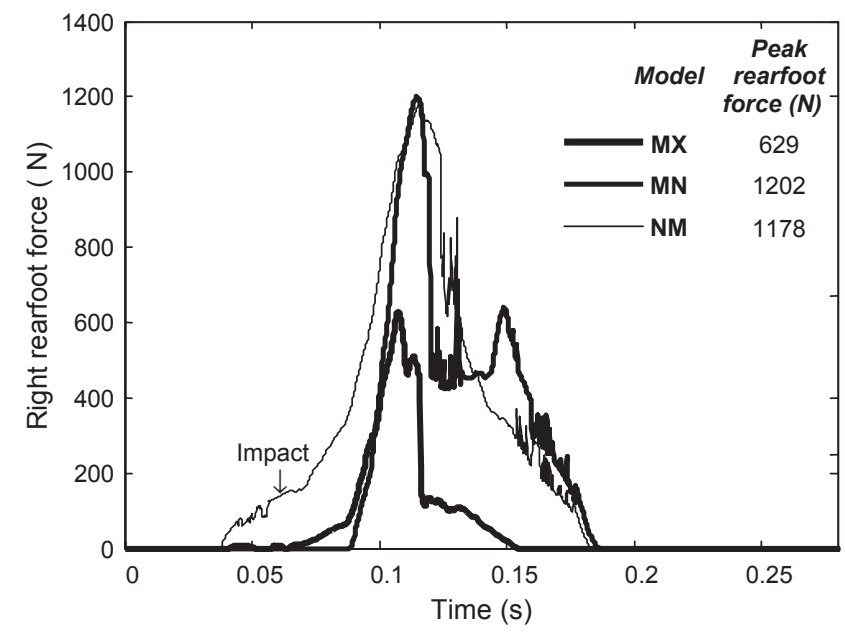

Fig. 6. External force on the rearfoot $\left(F_{\mathrm{RF}}\right)$ during initial braking and during the crash simulation for all models. Peak $F_{\mathrm{RF}}$ force was greatest for the model with no muscles (NM) and smallest for the panic braking model (MX). The time of vehicle impact is indicated.

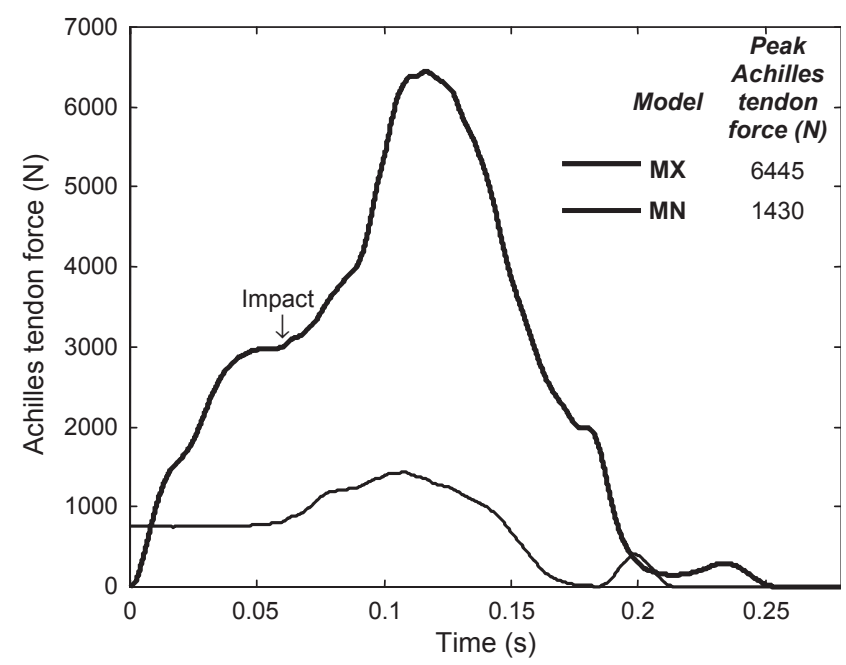

Fig. 7. Achilles tendon force $\left(F_{\mathrm{AT}}\right)$ during initial braking and during the crash simulation for the models with muscles. The panic braking model (MX) produced greater than four times the peak $F_{\mathrm{AT}}$ exhibited by the model with minimal muscle activation (MN). The time of vehicle impact is indicated. 
Minimal activation of the muscles caused intermediate values of peak ankle force (3327 N, Fig. 8).

The crash simulations provided a reasonable qualitative reproduction of a rigid body model kinematic response to frontal impact compared to other computational models (Fig. 9; Crandall et al., 1996; Kitagawa et al., 1998a,b). Comparison between the kinematic response (Fig. 9) and the force responses (Figs. 6-8) shows that the peak force occurs very early in kinematic response. With maximal muscle activation, the forward motion of the trunk is less than during minimal-effort braking, and there is increased deformation in the contact between forefoot and toepan (Figs. 9d and h).

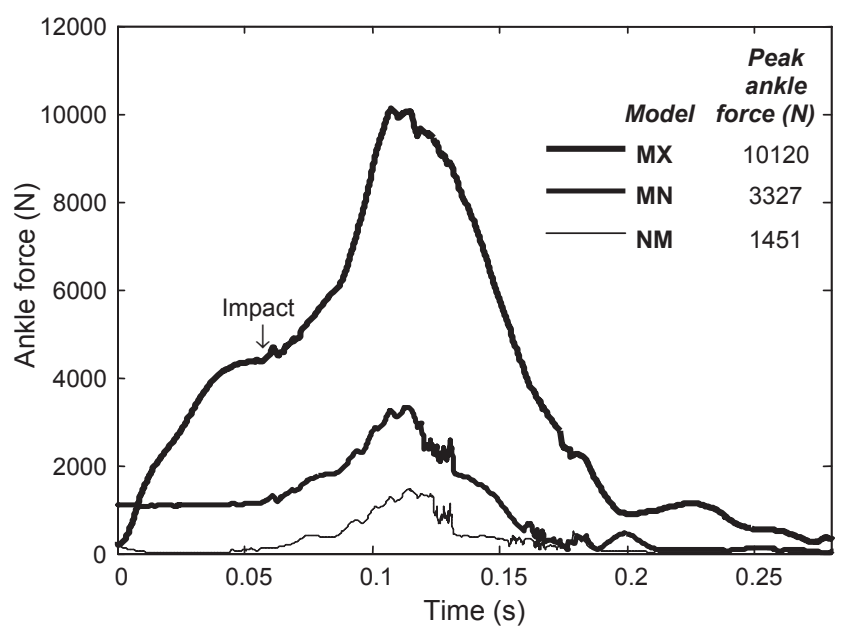

Fig. 8. Ankle force $\left(F_{\mathrm{AJ}}\right)$ during initial braking and during the crash simulation for all models. The greatest peak $F_{\mathrm{AJ}}$ existed in the panic braking model (MX) whereas the lowest was found in the model with no muscles (NM). The time of vehicle impact is indicated.

\section{Discussion}

The aim of this study was to determine how muscles influence foot and ankle forces during an automobile collision. We found that including muscle properties in a rigid body model affected peak external and internal force in the foot and ankle, and that muscle activation magnitude greatly intensified peak internal forces while lessening peak external force on the rearfoot.

To focus on the role that muscle properties play in foot and ankle injuries we limited this study to the sagittal plane. A similar planar model was capable of predicting external forces during running (Cole et al., 1996a), but was not validated for seated impacts. A previous collision research study which modeled lower extremity muscles as Hill models validated their model with pendulum impacts to human subjects (Cappon et al., 1999), but this validation would be more relevant to toepan intrusion than to vehicle deceleration. Our results are representative for accidents with fairly severe deceleration from vehicle-to-vehicle frontal impact at $61.5 \mathrm{~km} \mathrm{~h}^{-1}$. Intrusion was not simulated because deceleration alone is an injury risk factor (Burgess et al., 1995; Crandall et al., 1998) and because foot and ankle injuries seem to occur prior to intrusion (Kitagawa et al., 1998a,b). In the modeling of the vehicle interior, pedal geometry was not separately represented and contact between the knee and the instrument panel was not modeled. Such contact could lead to additional injuries at the knee, but at a later time than the peak forces in foot and ankle (Fig. 9). Although our model was limited by a rigid foot, the contact between the foot and toepan was compliant to account for all deformation in the foot. Simulation of the role of foot inversion and abduction during braking (Parenteau

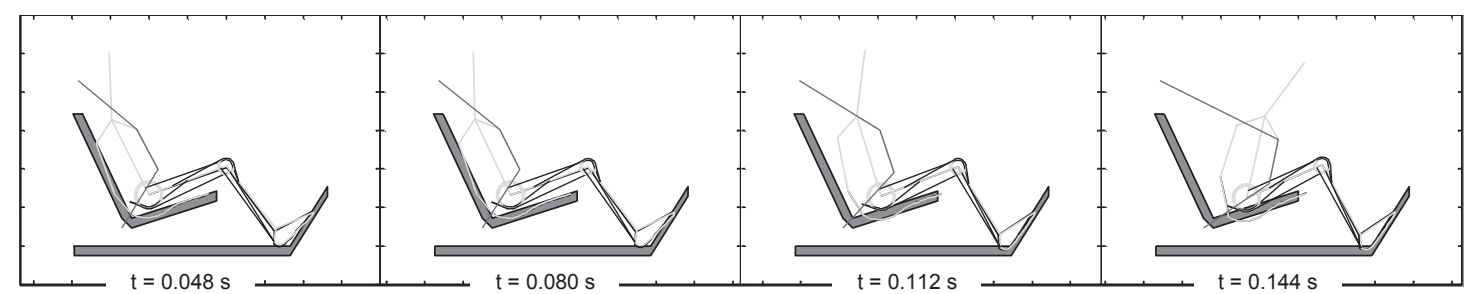

(a)

(b)

(c)

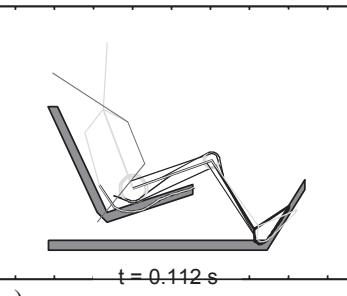

(g) (d)

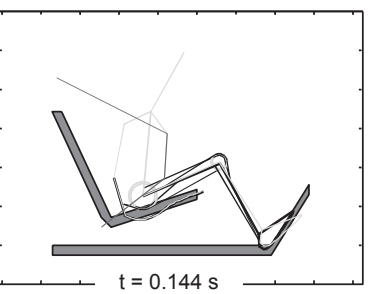

(h)

Fig. 9. Kinematic response of the model during minimal muscle activation (a-d) and during maximal muscle activation (e-h). Vehicle impact occurred at $0.064 \mathrm{~s}$. At maximal muscle activation, there is slightly less forward motion of the trunk. There is also increased force, and hence deformation, between foot and toepan in that condition. 
et al., 1996; Rudd et al., 1998) would require a more complex three dimensional model.

A modification to our previous muscle model (Cole et al., 1996a; Neptune et al., 2000) was made by replacing the parallel elastic element (PEE) with passive joint moments, leaving a two component Hill-based model. This was mechanically equivalent to placing the PEE in parallel to the CE and SEE (Jewell and Wilkie, 1958), and lumping together all PEE effects of muscles crossing the same joint. The advantage to this approach was that the passive properties of the limb could be modeled directly using recently published comprehensive data (Reiner and Edrich, 1999), while still representing the passive coupling between joints due to passive forces in biarticular muscles. We numerically simulated to what extent this rearrangement of muscle passive elements may have influenced the response of an active muscle to constant velocity stretch (Cole et al., 1996b). We found a small $(<5 \%)$, but constant difference and concluded that this limitation would not influence our results. It should also be noted that passive muscle force was not included in the calculation of Achilles tendon force and ankle joint force. Fig. 9, however, shows that the joints have not moved much from their initial angle at the time of peak force, suggesting that passive muscle forces are still low at that time.

In initiating a simulation with active muscles, the initial conditions must represent a steady state of the model. Steady state initial conditions, i.e. all forces in equilibrium, were guaranteed for $\mathrm{MN}$ because of the 4-s pre-impact simulation. Because it was important to use the same driving posture in all simulations, the MX and NM simulations were started from the same initial condition. While this was not a steady state, a new equilibrium was approached prior to the time of vehicle impact (Figs. 6-8). The MX model was slowly pushing itself out of the seat, but due to seat friction this was sufficiently slow that it did not interfere with the goal of using the same initial posture in all simulations.

Our NM and MN results were similar to peak ankle forces in other numerical models (Kitagawa et al., 1998a, b; Rudd et al., 1998). Our panic braking model (MX) produced over two times the highest ankle force $(10.1 \mathrm{kN})$ previously predicted by numerical simulations (Kitagawa et al., 1998a,b; Rudd et al., 1998). This discrepancy may signify a previous underestimation from how muscles were modeled, such as only including joint rotational stiffness due to muscles (Rudd et al., 1998) or representing muscles as Kelvin elements (Kitagawa et al., 1998a,b) whereas our MN and MX models included tensile forces on the skeleton as well as muscle properties. On the other hand, a previous model which incorporated Hill-based muscle properties (Cappon et al., 1999) at an activation level of only $30 \%$ exhibited a similar peak ankle force to that of our panic braking model (100\% activation), but this was a simulation of toepan intrusion rather than deceleration. Furthermore, the model of Cappon et al. (1999) did not include a SEE, which could have resulted in infinite short-range muscle stiffness (Cole et al., 1996b) and overestimation of impact forces.

Panic braking (MX) produced a peak ankle force of $10.1 \mathrm{kN}$ which is within the range of failure loads obtained from cadaver tests. Cadaveric fracture loads vary widely due to specimen age and bone mineral density (Kitagawa et al., 1998a, b; Seipel et al., 2001; Yoganandan et al., 2000). For instance, calcaneal fracture loads ranged from 3.6 to $11.4 \mathrm{kN}$ with $50 \%$ probability of fracture from 5.5 to $9.3 \mathrm{kN}$ (Crandall et al., 1996; Seipel et al., 2001). Calcaneal fractures also occurred at distal tibial loads of 7.8-8.1 kN (Kitagawa et al., 1998a, b; Yoganandan et al., 2000), while pylon (compression) fractures of the tibia happened at slightly lower loads $(\sim 7 \mathrm{kN})$ (Kitagawa et al., 1998a, b; Yoganandan et al., 2000). Our results show that panic braking during such a collision can produce a tibial pylon fracture as well as rupture of the Achilles tendon. The mechanism of Achilles tendon failure is a combination of strong triceps surae contraction and external loading on the foot (Wren et al, 2001) at tendon loads ranging from 2.1 to $6.5 \mathrm{kN}$ signifying that rupture or avulsion was likely during our panic braking simulation (peak $F_{\mathrm{AT}}=6.4 \mathrm{kN}$ ).

We found that muscle activation greatly intensified peak internal forces while lessening the peak external force on the rearfoot. Obviously, muscle activation level could exacerbate axial loading injuries, such as tibial fractures, as has been shown by others using cadaver surrogates and numerical simulations (Cappon et al., 1999; Crandall et al., 1996; Funk et al., 2002; Kitagawa et al., 1998a, b; McMaster et al., 2000; Parenteau et al., 1996; Rudd et al., 1998). The relationship between muscle activation and the subsequent external and internal forces during a collision was complex. Even a low magnitude of muscle activation (MN) had a strong effect on internal forces, but not on external forces. For example, peak ankle forces after impact from $\mathrm{MN}$ were more than double that of the model without muscles (NM, Figs. 8 and 10), yet external forces were similar (Figs. 6 and 10). Furthermore, when muscle activation went from minimal to maximal, there was a greater than fourfold increase in Achilles tendon force after impact (Figs. 7 and 10), yet joint loading only tripled, primarily due to the decreased external reaction force accompanying greater muscle activation (Figs. 6-8). Muscle forces reduced the external force $\left(F_{\mathrm{RF}}\right)$ because the foot was held in plantarflexion on the pedal, thus slowing the motion of the heel towards the toepan and mitigating external impact force. This mechanism can be observed in cadaver experiments and may result in fewer calcaneal fractures, but more pylon fractures of 


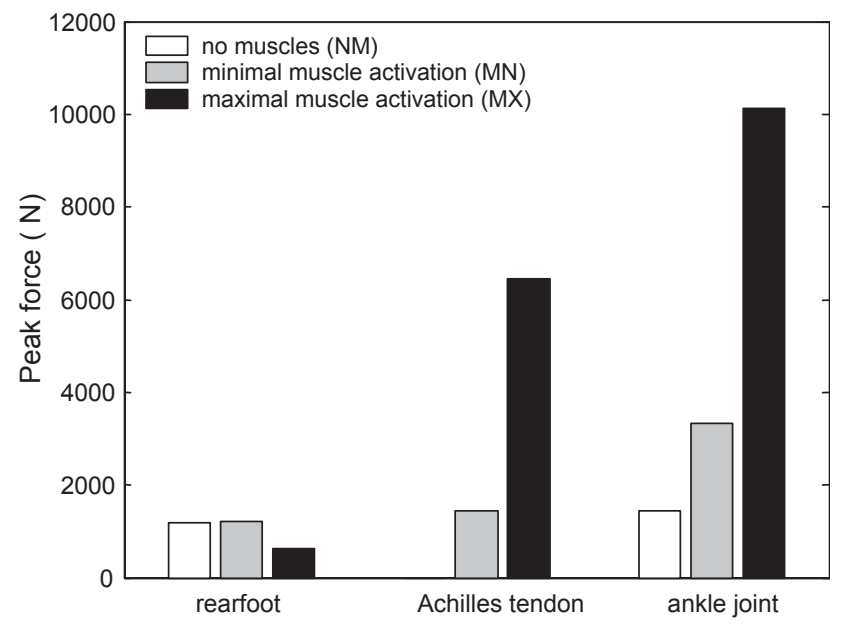

Fig. 10. Peak external and internal forces in each of the three models.

the tibia (Funk et al., 2002). The quadrupling of peak Achilles tendon force from MN to MX is due not only to increased activation, but also to the force-velocity and force-length relationship in muscle, specifically during an eccentric contraction when high force production is possible. This force increase in activated muscle due to rapid stretching caused by impact might be called an "active response", though activation is not changed. These internal and external force relationships highlight the potentially complex effects of muscles on forces and kinematics on the driver's lower extremity during a vehicle collision.

The influence of muscle properties thus appears to be significant. Manipulating muscle activation or contractile element behavior is one unique advantage of computational musculoskeletal models in predicting the influence of muscle properties on collision injuries. Cadaver models do not only lack muscle activation and muscle properties, but also the influence of the wholebody response on foot and ankle forces.

In light of our findings, we conclude that (1) active braking could exacerbate lower extremity injuries during vehicle collisions, and (2) active braking can lead to an inverse relationship between external and internal forces in the lower extremity during a vehicle collision.

\section{Acknowledgements}

This research was supported by the Aircast Foundation.

\section{References}

Aerts, P., De Clercq, D., 1993. Deformation characteristics of the heel region of the shod foot during a simulated heel strike: the effect of varying midsole hardness. Journal of Sports Sciences 11, 449-461.
Beillas, P., Begeman, P.C., Yang, K.H., King, A.I., Arnoux, P.-J., Kang, H.-S., Kayvantash, K., Brunet, C., Cavallero, C., Prasad, P., 2001. Lower limb: advanced FE model and new experimental data. Stapp Car Crash Journal, 45, 469-493.

Burgess, A.R., Dischinger, P.C., O'Quinn, T.D., Schmidhauser, C.B., 1995. Lower extremity injuries in drivers of airbag-equipped automobiles: clinical and crash reconstruction correlations. The Journal of Trauma: Injury Infection and Critical Care 38 (4), 509-516.

Cappon, H.J., van den Kroonenberg, A.J., Happee, R., Wismans, J., 1999. An improved lower leg multibody model. In: Charpenne, A., Mackay, M. (Eds.), Proceedings to the International Conference on the Biomechanics of Impacts IRCOBI, Sitges, Barcelona, Spain, pp. $499-512$.

Code of Federal Regulations: Seat Belt Assemblies, 2000. Federal Motor Vehicle Safety Standards, 49CFR571.209, DOT, Washington, DC, http://www.access.gpo.gov/nara/cfr/waisidx_00/49cfr571_ 00.html.

Cole, G.K., Nigg, B.M., van den Bogert, A.J., Gerritsen, K.G., 1996a. Lower extremity joint loading during impact in running. Clinical Biomechanics 11 (4), 181-193.

Cole, G.K., van den Bogert, A.J., Herzog, W., Gerritsen, K.G., 1996b. Modeling of force production in skeletal muscle undergoing stretch. Journal of Biomechanics 29 (8), 1091-1104.

Crandall, J.R., Portier, L., Petit, P., Hall, G.W., Bass, C.R., Klopp, G.S., Hurwitz, S., Pilkey, W.D., Trosseille, X., Tarriere, C., Lassau, J., 1996. Biomechanical properties of the leg, foot and ankle. In: Proceedings of the 40th Stapp Car Crash Conference. Society of Automotive Engineers 962424, pp. 173-192.

Crandall, J.R., Martin, P.G., Sieveka, E.M., Pilkey, W.D., Dischinger, P.C., Burgess, A.R., O'Quinn, T.D., Schmidhauser, C.B., 1998. Lower limb response and injury in frontal crashes. Accident Analysis and Prevention 30 (5), 667-677.

Dempster, W.T., 1956. The anthropometry of body action. Annals New York Academy of Sciences 63, 559-585.

Digges, K.H., Bedewi, P.G., Nahouth, G.T., Bedewi, N.E., Augenstein, J., Perdeck, E., Stratton, J., 1995. Determination and modeling of ankle injury causation. In: Proceedings to the International Conference on Pelvic and Lower Extremity Injuries. Washington, DC.

Dubbeldam, R., Nilson, G., Pal, B., Eriksson, N., Owen, C., Roberts, A., Crandall, J., Hall, G., Manning, P., Wallace, A. (1999). A MADYMO model of the foot and leg for local impacts. Presented at the 43rd Stapp Car Crash Conference, SAE 99SC12.

Funk, J.R., Crandall, J.R., Tourret, L.J., MacMahon, C.B., Bass, C.R., Patrie, J.T., Khaewpong, N., Eppinger, R.H., 2002. The axial injury tolerance of the human foot/ankle complex and the effect of achilles tension. Journal of Biomechanical Engineering 124 (6), 750-757.

Gerritsen, K.G.M., van den Bogert, A.J., Hulliger, M., Zernicke, R.F., 1998. Intrinsic muscle properties facilitate motor control-a computer simulation study. Motor Control 2, 206-220.

Goffe, W.L., Ferrier, G.D., Rogers, J., 1994. Global optimization of statistical functions with simulated annealing. Journal of Economics 60, 65-99.

Iwamoto, M., Tamura, A., Furusu, K., Kato, C., Miki, K., Hasegawa, J., Yang, K.H., 2000. Development of a finite element model of the human lower extremity for analyses of automotive crash injuries. Computer Applications for Crash, Optimization, and Simulation Research. Warrendale, PA, 2000-01-0621, pp. 139-146.

Jewell, B.R., Wilkie, D.R., 1958. An analysis of the mechanical components of frog's striated muscle. Journal of Physiology 143, 515-540.

Kitagawa, Y., Ichikawa, H., King, A.I., Levine, R.S., 1998a. A severe ankle and foot injury in frontal crashes and its mechanism. In: 
Proceedings of the 42nd Stapp Car Crash Conference. Society of Automotive Engineers 983145, pp. 1-12.

Kitagawa, Y., Ichikawa, H., Pal, C., King, A.I., Levine, R. S., 1998b. Lower leg injuries caused by dynamic axial loading and muscle tensing. Proceedings to the 16th International Technical Conference on Experimental Safety Vehicles. Vol. II. Washington, DC, NHTSA, pp. 1597-1607. Report No. 98-S7-O-09.

MacKensie, E.J., Cushing, B.M., Jurkovich, G.J., 1993. Physical impairment and functional outcomes six months after severe lower extremity fractures. Journal of Trauma 34, 528-561.

Manning, P., Wallace, A., Owen, C., Roberts, A., Oakley, C., Lowne, R., 1998. Dynamic response and injury mechanism in the human foot and ankle and an analysis of dummy biofidelity. In: Proceedings to the 16th International Technical Conference on the Enhanced Safety of Vehicles. Windsor, Ontario, pp. 1960-1998.

Martin, P.G., Crandall, J.R., Pilkey, W.D., Miller, T.R., 1997. Passenger car drivers: annual injury incidence and costs projected to 2005. In: Proceedings to the Association for the Advancement of Automotive Medicine. Orlando, FL.

Martin, P.G., Crandall, J.R., Pilkey, W.D., 2000. Injury trends of passenger car derivers in frontal crashes in the USA. Accident Analysis and Prevention 32, 541-557.

Mazzae, E.N., Barickman, F., Baldwin, G.H.S., Forkenbrock, G., 1999. Driver crash avoidance behavior with ABS in an intersection incursion scenario on dry versus wet pavement. Society of Automotive Engineers 1999-01-1288, Warrendale, PA.

McMaster, J., Parry, M., Wallace, W.A., Wheeler, L., Owen, C., Lowne, R., Oakley, C., Roberts, A.K., 2000. Biomechanics of ankle and hindfoot injuries in dynamic axial loading. Proceedings to the 44th Stapp Car Crash Conference, Stapp Car Crash Journal 44, 357-377.

Neptune, R.R., Wright, I.C., van den Bogert, A.J., 2000. The influence of orthotic devices and vastus medialis strength and timing on patellofemoral loads during running. Clinical Biomechanics 15, 611-618.

Pattimore, D., Ward, E., Thomas, P., Bradford, M., 1990. The nature and the cause of lower limb injuires in car crashes. In: Proceedings to the 34th Stapp Car Crash Conference. Society of Automotive Engineers 912901, pp. 177-188.

Parenteau, C.S., Viano, D.C., Lovsund, P., Tingvall, C., 1996. Footankle injuries: influence of crash location, seating position and age. Accident Analysis and Prevention 28 (5), 607-617.
Partyka, S., Backaitis, S., 1995. Comparison on driver/passenger and right/left lower leg injuries in frontal crashes. In: Proceedings to the Pelvic and Lower Extremity Injuries Conference. Washington, DC.

Pletschen, B., Scheunert, D., Deubert, M., Hermann, R., Zeidler, F., 1990. Application of the injury cost scale (ICS) to MercedesBenz accident data. In: Proceedings to the 34th Stapp Car Crash Conference. Society of Automotive Engineers 902331, pp. 357-369.

Reiner, R., Edrich, T., 1999. Identification of passive elastic joint moments in the lower extremities. Journal of Biomechanics 32, 539-544.

Robbins, D.H., 1983. Anthropometric specifications for a mid-sized male dummy. Vol. 2. US Department of Transportation DTNH2280-C-07502, Washington, DC.

Rudd, R.W., Sieveka, E.M., Crandall, J.R., Pellettiere, J., Lynn, S., Keller, J., 1998. Lower extremity and brake pedal interaction in frontal collisions: computer simulation. Mechanics of Protection $1355,125-132$.

Seipel, R.C., Pintar, F.A., Yoganandan, N., Boynton, M.D., 2001. Biomechanics of calcaneal fractures: a model for the motor vehicle. Clinical Orthopaedics 388, 218-224.

Tamura, A., Furusu, K., Miki, K., Hasegawa, J., Yang, K.H., 2001. A tibial mid-shaft injury mechanism in frontal automotive crashes. Proceedings to the 17th International Technical Conference on the Enhanced Safety of Vehicles (ESV), Amsterdam, The Netherlands.

Wilson, L.S., Mizel, M.S., Michelson, J.D., 2001. Foot and ankle injuries in motor vehicle accidents. Foot and Ankle International $22(8), 649-652$.

Winters, 1990. Chapter.

Wren, T.A., Yerby, S.A., Beaupre, G.S., Carter, D.R., 2001. Influence of bone mineral density, age, and strain rate on the failure mode of human achilles tendons. Clinical Biomechanics 16 (6), 529-534.

Wright, I.C., Neptune, R.R., van den Bogert, A.J., Nigg, B.M., 1998. Passive regulation of impact forces in heel-toe running. Clinical Biomechanics 13, 521-531.

Winter, David.A., 1990. Biomechanics and Motor Control of Human Movement 2nd Edition. Wiley, New York, NY.

Yoganandan, N., Pintar, F.A., Seipel, R., 2000. Experimental production of extra- and intra-articular fractures of the os calcis. Journal of Biomechanics 33, 745-749. 